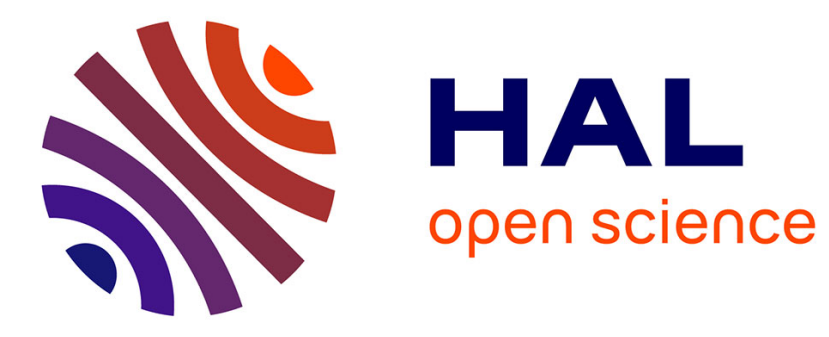

\title{
Hormonal deficiencies during and after Puumala hantavirus infection
}

\author{
S. Mäkelä, P. Jaatinen, M. Miettinen, J. Salmi, I. Ala-Houhala, H. Huhtala, \\ M. Hurme, I. Pörsti, A. Vaheri, J. Mustonen
}

\section{- To cite this version:}

S. Mäkelä, P. Jaatinen, M. Miettinen, J. Salmi, I. Ala-Houhala, et al.. Hormonal deficiencies during and after Puumala hantavirus infection. European Journal of Clinical Microbiology and Infectious Diseases, 2010, 29 (6), pp.705-713. 10.1007/s10096-010-0918-y . hal-00586477

\section{HAL Id: hal-00586477 https://hal.science/hal-00586477}

Submitted on 16 Apr 2011

HAL is a multi-disciplinary open access archive for the deposit and dissemination of scientific research documents, whether they are published or not. The documents may come from teaching and research institutions in France or abroad, or from public or private research centers.
L'archive ouverte pluridisciplinaire HAL, est destinée au dépôt et à la diffusion de documents scientifiques de niveau recherche, publiés ou non, émanant des établissements d'enseignement et de recherche français ou étrangers, des laboratoires publics ou privés. 
Diseases

Editorial Manager(tm) for European Journal of Clinical Microbiology \& Infectious

Manuscript Draft

Manuscript Number: EJCMID-D-10-00050R1

Title: Hormonal Deficiencies During and After Puumala Hantavirus Infection

Article Type: Article

Keywords: Puumala hantavirus; hemorrhagic fever with renal syndrome; hypogonadism; hypopituitarism; hypothyroidism

Corresponding Author: Dr. Satu Mäkelä, Ph.D., M.D.

Corresponding Author's Institution: Tampere University Hospital

First Author: Satu Mäkelä, Ph.D., M.D.

Order of Authors: Satu Mäkelä, Ph.D., M.D.; Pia Jaatinen, M.D., PhD; Marja Miettinen, M.D.; Jorma Salmi, M.D., PhD; Ilpo Ala-Houhala, M.D., PhD; Heini Huhtala, M.Sc.; Mikko Hurme, M.D., PhD; Ilkka Pörsti, M.D., PhD; Antti Vaheri, M.D., PhD; Jukka Mustonen, M.D.,PhD

Abstract: Purpose: Previous reports have described panhypopituitarism associated with severe cases of hemorrhagic fever with renal syndrome (HFRS), but the prevalence of hormonal deficiencies after nephropathia epidemica (NE), a milder form of HFRS, has not been studied. This study was conducted to determine the prevalence of hormonal defects in patients with acute NE and during long-term follow-up.

Methods: Fifty-four patients with serologically confirmed acute NE were examined by serum hormonal measurements during the acute NE, after 3 months, and after 1 to 10 (median 5) years.

Results: Thirty out of 54 (56\%) patients had abnormalities of the gonadal and/or thyroid axis during the acute NE. After a median follow-up of 5 years, 9 (17\%) patients were diagnosed with a chronic, overt hormonal deficit: hypopituitarism was found in 5 patients and primary hypothyroidism in 5 . In addition, chronic subclinical testicular failure was found in 5 men. High creatinine levels and inflammatory markers during NE associated with the acute central hormone deficiencies, but not with the chronic ones.

Conclusions: Hormonal defects are common during acute NE and surprisingly many patients develop chronic hormonal deficiencies after NE. The occurrence of long-term hormonal defects cannot be predicted by the severity of acute NE.

Response to Reviewers: Ms. No. EJCMID-D-10-00050

Hormonal Deficiencies During and After Puumala Hantavirus Infection

Point-by-point responses to the comments by Reviewer 1

Major points:

A. According to the reviewer's advice, we have now added two new tables (Tables 3 and 4) to clarify the presentation of the observations. Table 3 shows the clinical diagnoses and serial plasma hormone levels in those $9 \mathrm{NE}$ patients who presented with chronic, overt hormonal deficits. In Table 4, we show the acute-phase clinical and laboratory findings of the 9 patients, who developed chronic hormonal defects after NE, compared to those 45 patients, whose hormone levels remained normal 
during the follow-up. Since the clinical diagnoses of hormonal deficiencies are now shown in Table 3 (in the revised version), we have omitted the corresponding text from Results, Hormonal deficiencies: "Of these 9 patients, 2 were diagnosed with isolated central hypogonadism, 2 had multiple pituitary hormone deficiencies, 2 had primary hypothyroidism only, one had primary hypothyroidism and primary hypogonadism, one was diagnosed with isolated central hypogonadism and peripheral hypothyroidism, and one with primary hypothyroidism and a possible GH deficiency (undetectable GH level and IGF-1 $6.5 \mathrm{nmol} / \mathrm{l}$; reference range 10-29 nmol/l)." In order to further clarify the results, we have also referred to the patients described in Table 3 (e.g. "patient 1, table 3") in the revised text: Results, page 8, Hormonal deficiencies, lines 6 and 12, as well as in Results, Imaging studies, page 9, the first and the third line). We have omitted the following text from Results, Imaging studies: "Testo 11.610.8-8.1-7.4 nmol/l, LH 1.6-1.4-2.0-2.6 U/l, fT4 12.5-11.8-10.4-10.4 pmol/l, and TSH 1.2-1.1-1.0-0.9 $\mathrm{mU} / \mathrm{l}$, measured in the acute phase, and after 1 year, 5 and 9 years, respectively", since the same values are now shown in Table 3 (patient 2) of the revised version.

B. The reviewer correctly points out that in the original manuscript (Results, the second paragraph) the expression "Table 1 shows that serum median cortisol and PRL levels increased and Testo concentration decreased during the acute phase of NE" is misleading. We have now revised the sentence in page 7, the second line, as follows: "Table 1 shows that serum median cortisol and PRL levels were higher and Testo concentrations lower during the acute phase of NE".

Accordingly, we have revised the Discussion, the second line, as follows: "Serum cortisol and PRL levels were higher and serum Testo concentrations lower during acute NE compared to the corresponding values after 3 months".

C. The reviewer is right that it would have been valuable to include patients with other viral infections as controls, as we have clearly stated in the discussion (the penultimate paragraph). The findings of the present study give rise to controlled studies in the future. We were not quite sure if the reviewer wished for a table of the limitations of this study, but we did not make any, since there are already four tables in the manuscript.

Minor point: We have added a symbol ">" and a parenthesis to the page 6, Results, line 5: "Acute impairment of renal function (maximum plasma creatinine concentration measured during hospital stay $>100 \mu \mathrm{mol} / \mathrm{l}$ ) was observed in $78 \%$ of the patients, and 3 needed transient dialysis therapy".

Point-by-point responses to the comments by Reviewer 2

The diagnosis of PUUV infection is based on serological tests, detection of PUUV IgM or low avidity of PUUV IgG. In Finland, PUUV is the only hantavirus that causes HFRS. We have now added a more detailed description of the serological test in the revised manuscript on page 4, line 2: "The original patient group consisted of 70 prospectively collected consecutive patients, hospitalized due to serologically verified acute PUUV infection at Tampere University Hospital, Finland, during the years 1997 to 1999. The specific serological diagnosis was based on an immunoglobulin M-capture enzyme immunoassay and PUUV Sotkamo strain full-length $\mathrm{N}$ protein expressed by using the baculovirus system in Sf9 insect cells [18]. In comparison with various other protocols the assay showed optimal sensitivity and specificity [19]". We have also added a new reference 19: Sjölander, K.B., Elgh, F., KallioKokko, H et al. (1997) Evaluation of serological methods for diagnosis of Puumala hantavirus infection (nephropathia epidemica). J Clin Microbiol 35, 3264-3268. 


\section{Hormonal Deficiencies During and After Puumala Hantavirus Infection}

Satu Mäkelä ${ }^{1,2}$, Pia Jaatinen ${ }^{1,2}$, Marja Miettinen ${ }^{3}$, Jorma Salmi ${ }^{1}$, Ilpo Ala-Houhala ${ }^{1,2}$, Heini Huhtala ${ }^{4}$, Mikko

Hurme $^{2}$, Ilkka Pörsti ${ }^{1,2}$, Antti Vaheri ${ }^{5}$, and Jukka Mustonen ${ }^{1,2}$

Affiliations and addresses: ${ }^{1}$ Department of Internal Medicine, Tampere University Hospital, P.O. Box 2000,

33521 Tampere, ${ }^{2}$ Medical School, FIN-33014 University of Tampere, ${ }^{3}$ Department of Internal Medicine, Central Hospital of Jyväskylä, Keskussairaalantie 19, 40620 Jyväskylä, ${ }^{4}$ Tampere School of Public Health, FIN-33014

University of Tampere, ${ }^{5}$ Department of Virology, Haartman Institute, P.O. Box 21, 00014 University of Helsinki, Finland

\section{Correspondence:}

Satu Mäkelä, MD, PhD

Department of Internal Medicine, Tampere University Hospital

P.O. Box 2000, FI-33521 Tampere, Finland

Tel.: +3583311 611, Fax: +358331164368

e-mail: satu.marjo.makela@uta.fi 


\begin{abstract}
Purpose: Previous reports have described panhypopituitarism associated with severe cases of hemorrhagic fever with renal syndrome (HFRS), but the prevalence of hormonal deficiencies after nephropathia epidemica (NE), a milder form of HFRS, has not been studied. This study was conducted to determine the prevalence of hormonal defects in patients with acute NE and during long-term follow-up.
\end{abstract}

Methods: Fifty-four patients with serologically confirmed acute NE were examined by serum hormonal measurements during the acute NE, after 3 months, and after 1 to 10 (median 5) years.

Results: Thirty out of $54(56 \%)$ patients had abnormalities of the gonadal and/or thyroid axis during the acute NE. After a median follow-up of 5 years, $9(17 \%)$ patients were diagnosed with a chronic, overt hormonal deficit: hypopituitarism was found in 5 patients and primary hypothyroidism in 5 . In addition, chronic subclinical testicular failure was found in 5 men. High creatinine levels and inflammatory markers during NE associated with the acute central hormone deficiencies, but not with the chronic ones.

Conclusions: Hormonal defects are common during acute NE and surprisingly many patients develop chronic hormonal deficiencies after NE. The occurrence of long-term hormonal defects cannot be predicted by the severity of acute NE.

Keywords: Puumala hantavirus, hemorrhagic fever with renal syndrome, hypogonadism, hypopituitarism, hypothyroidism 


\section{Introduction}

Nephropathia epidemica (NE) is a form of hemorrhagic fever with renal syndrome (HFRS), caused by Puumala hantavirus (PUUV) [1]. PUUV along with its host, the bank vole (Myodes glareolus), is found all over Europe, excluding the Mediterranean region. In Finland, 1000-3000 serologically verified cases occur annually and the average PUUV seroprevalence in the population is $5 \%$. Other hantaviruses causing HFRS include Hantaan (HTNV), Dobrava (DOBV), Saaremaa, and Seoul viruses, while several others found in Americas cause hantavirus cardiopulmonary syndrome [1]. NE is clinically characterized by fever, headache, nausea, backache and abdominal pain, as well as transient renal insufficiency [2-4]. Hemorrhages are rare. Complete recovery from NE is the usual outcome, but a convalescent phase with fatigue may last for months [2-4]. Genetic susceptibility seems to determine the severity of NE, as individuals with the HLA B8 DRB1*0301 haplotype have been shown to suffer from a severe form of the disease [5], while the HLA B27 allele correlates with a mild clinical course [6].

There are case reports of hypophyseal hemorrhage and panhypopituitarism in patients with acute NE [7-11]. Postmortem studies of patients with HTNV-induced HFRS, as well as in the few fatal cases of NE, have revealed hemorrhage and necrosis of the pituitary gland in 50-100 \% of the autopsies [11-13]. PUUV antigen has been detected in hypophyseal neuroendocrine and endothelial cells of a patient with fatal NE [8]. In a recent retrospective Serbian study of 60 adults with a previous HFRS, a high prevalence of hypopituitarism was identified after recovery from HFRS [14]. Immunological factors including tumor necrosis factor alpha (TNF- $\alpha)$ and interleukin-6 (IL-6) have been suggested to be involved in the pathogenesis of NE [15]. Cytokines produced in inflammatory foci may also cause changes in the endocrine system, including activation of the hypothalamicpituitary-adrenal (HPA) axis [16, 17].

In the present study we examined the prevalence of hormonal abnormalities in hospital-treated patients with NE, during both the acute illness and long-term follow-up. We also studied whether the hormonal abnormalities associated with NE were related to the clinical severity of the acute illness, the intensity of the cytokine response (plasma IL-6 and TNF- $\alpha$ levels), or the immunogenotype of the patient (HLA-B8, -DR3 and B27 alleles).

\section{Materials and Methods}

\section{Subjects}

The original patient group consisted of 70 prospectively collected consecutive patients, hospitalized due to 
serologically verified acute PUUV infection at Tampere University Hospital, Finland, during the years 1997 to

1999. The specific serological diagnosis was based on an immunoglobulin M-capture enzyme immunoassay and PUUV Sotkamo strain full-length N protein expressed by using the baculovirus system in Sf9 insect cells [18]. In comparison with various other protocols the assay showed optimal sensitivity and specificity [19]. Fifty-four of the patients attended the 12-month follow-up visit, and they comprised the present study population. The median patient age was 42 years (range 15-70 years), and 37 (69\%) of them were male. Fourteen patients had previous diseases: hypertension in four patients, hypothyroidism in two, as well as ankylosing spondylarthritis, bronchial asthma, aortic valve disease, coeliac disease, sequel of renal tuberculosis, operated cancer of the vocal cords, operated meningeoma and osteoporosis in one each. All the patients continued their regular medications during the study, including two patients with L-thyroxine substitution for hypothyroidism. None of the patients received corticosteroid therapy, or any other drug that could possibly affect plasma hormone concentrations, except for the two patients on L-thyroxine substitution therapy. One female patient was breast-feeding during acute NE and her estradiol (E2), follicle-stimulating hormone (FSH) and prolactin (PRL) values were excluded from the analyses. The Ethics Committee of Tampere University Hospital approved the study and every patient gave a written informed consent to participate.

\section{Study protocol}

All the patients were examined during their hospital stay. Detailed medical histories were obtained, and a careful physical examination was performed. All blood specimens were obtained between $0730-0930 \mathrm{~h}$ in the morning. Blood samples for plasma creatinine, C-reactive protein (CRP), IL-6, TNF- $\alpha$, and blood cell counts, as well as 24-h urinary protein excretion were collected on three consecutive mornings after hospital admission. The first blood sample for hormonal analyses was obtained on the first morning of hospital care, and the second sample was taken on the third morning. The highest or the lowest value of each variable measured during hospitalization was designated as the maximum or the minimum value, respectively. All the serum samples for hormone analyses were stored at $-70^{\circ} \mathrm{C}$ until analyzed.

The patients were scheduled to an outpatient examination 3 and 12 months after the acute disease. Forty-nine patients attended the 3-month visit (74 to 146 days, median 102 days after admission), and 54 the 12 month visit. The last prearranged follow-up visit was organized in 2004 (4 to 7 years, median 5 years after NE), and 38 patients participated. All serum hormonal levels were analyzed in 2007. Due to the hormonal results, we 
invited six patients to an additional visit in 2008 (9 to 10 years, median 10 years after NE), and they underwent physical, laboratory and imaging studies, as appropriate (see Methods).

\section{Methods}

Plasma creatinine and CRP concentration, blood cell counts, and 24-h urinary protein excretion were determined by standard laboratory methods. Plasma IL- 6 and TNF- $\alpha$ concentrations were determined using enzyme-linked immunosorbent assays (PeliKine Compact ${ }^{\mathrm{TM}}$ human IL-6 and TNF- $\alpha$ kits, Red Cross Blood Transfusion Service, Amsterdam, The Netherlands). The analyses of the alleles HLA-B8, -DR3 and -B27 were performed as described elsewhere [20].

Serum free thyroxine (fT4) and thyrotropin (TSH) were measured by a chemiluminescent microparticle immunoassay (Abbott Architect i2000 system, Abbott Laboratories, IL, USA), cortisol, PRL, luteinizing hormone (LH), and FSH by fluoroimmunoassay (1235 AutoDELFIA, Wallac Ltd, Turku, Finland), and E2 as well as testosterone (Testo) by radioimmunoassay (1277 Gammamaster, Wallac Ltd). The six patients invited to an additional visit in 2008 were also studied for serum levels of growth hormone (GH) by timeresolved fluoroimmunoassay (AutoDELFIA hGH, Wallac Ltd), insulin-like growth factor 1 (IGF-1) by immunoluminometric assay (DiaSorin Liaison IGF1, Saluggia, Italy), antibodies against thyroid peroxidase (TPOAb) by immunoluminometric assay (Abbott Architect Anti-TPO, Wiesbaden, Germany), as well as for adrenocortical function by standard $250 \mu \mathrm{g}$ ACTH stimulation test.

The reference ranges were 9.0-19.0 pmol/1 for fT4, 0.4-4.0 mU/1 for TSH, 180-680 nmol/1 for cortisol, $<450 \mathrm{mU} / \mathrm{l}$ for PRL in male patients, $<600 \mathrm{mU} / 1$ in premenopausal women, and $<280 \mathrm{mU} / \mathrm{l}$ in postmenopausal women. The male reference ranges were 10.4-34.6 nmol/l for Testo, and 0.7-6.7 U/1 for LH. As the phase of menstrual cycle was not known, E2 below $0.1 \mathrm{nmol} / \mathrm{l}$ was regarded as a hypogonadal value for a premenopausal woman. GH reference range was 0-11.5 mU/l, and the age-specific reference values for IGF-1 were 19-65 nmol/1 at $18-20 \mathrm{y}, 15-45 \mathrm{nmol} / \mathrm{l}$ at $21-30 \mathrm{y}, 14-36 \mathrm{nmol} / \mathrm{l}$ at $31-50 \mathrm{y}, 10-29 \mathrm{nmol} / \mathrm{l}$ at $51-70 \mathrm{y}$ and $8-23 \mathrm{nmol} / \mathrm{l}$ over 70 years of age. TPOAb reference range was $<6 \mathrm{U} / \mathrm{ml}$. Cortisol response exceeding $550 \mathrm{nmol} / \mathrm{l}$ was considered normal in the ACTH test.

Peri- and postmenopausal women were not analyzed for defects of the gonadal axis, as they were hypogonadal by definition. However, their FSH and E2 levels were included in the analysis of hormonal alterations between the acute illness and 3 months afterwards. Chronic, overt hypogonadism was defined as Testo (in men) or E2 (in premenopausal women) repeatedly below the reference range one year or more after the 
acute NE. Chronic, subclinical/compensated testicular failure was diagnosed in a male patient with chronically below $9.0 \mathrm{pmol} / \mathrm{l}$ and/or TSH repeatedly above $4.0 \mathrm{mU} / \mathrm{l}$ in a patient with chronic thyroiditis, goiter, and/or symptoms suggestive of hypothyroidism [21].

Thyroid ultrasound imaging (Vivid I, GEMS Ultrasound, Tirat Carmel, Israel) was performed by the same investigator (P.J.) on the six patients attending the additional visit in 2008. The hypothalamic-pituitary region was studied by magnetic resonance imaging (MRI, MAGNETOM Trio 3-Tesla scanner, Siemens, Erlangen, Germany) in the patients showing distinct hormonal deficits of central origin.

\section{Statistics}

To describe the data, medians (ranges) were given for continuous variables and percentages for categorical variables. Comparisons between the groups were made with Mann-Whitney U-test for continuous variables, while Pearson chi-square test or Fisher's exact test was used for categorical data. Wilcoxon signed-rank test was used to evaluate changes in serum hormone levels between the acute phase of NE and 3 months afterwards, and between 3 months and 1 year or 5 years, respectively. Correlations were calculated by means of Spearman's rank correlation coefficient. A p-value of less than 0.05 in two-sided testing was considered statistically significant. Statistical analyses were performed using SPSS for Windows version 7.5 (SPSS Inc., Chicago, IL, USA).

\section{Results}

Clinical and laboratory findings during acute NE

The clinical picture was typical of acute NE in all patients. All had fever lasting for a median of 5 days (range 2 to 14 days). Ten (19\%) received empirical antibiotics, but in none of them could a bacterial infection be confirmed. Acute impairment of renal function (maximum plasma creatinine concentration measured during hospital stay $>100 \mu \mathrm{mol} / \mathrm{l}$ ) was observed in $78 \%$ of the patients, and 3 needed transient dialysis therapy. Thrombocytopenia (blood platelet count $<150 \times 10^{9} / 1$ ) was present in all patients, but none had major bleeding complications. Hypotension (systolic blood pressure $<90 \mathrm{mmHg}$ ) was observed on admission in 3 patients, and was corrected by fluid infusion. 


\section{Serum hormone levels during the acute phase of $N E$}

Table 1 shows that serum median cortisol and PRL levels were higher and Testo concentrations lower during the acute phase of NE, compared to the corresponding values after 3 months. Serum median LH level did not change. There were, however, remarkable individual differences in the direction and magnitude of serum Testo and LH alterations (Figure 1). Serum TSH level was slightly higher and FSH concentration lower during the acute phase than after 3 months (Table 1). There were no differences between the median hormone levels (cortisol, PRL, fT4, TSH, Testo, LH, E2 and FSH) measured at 3 months compared to the levels measured after 1 or 5 years (data not shown).

Serum cortisol concentration during acute NE correlated positively with maximum plasma creatinine and IL-6 levels ( $r=0.352, p=0.009$, and $r=0.319, p=0.019$, respectively), with blood leukocyte count $(r=0.370$, $\mathrm{p}=0.006)$, and with serum PRL level ( $\mathrm{r}=0.402, \mathrm{p}=0.003)$. Similarly, serum PRL level correlated with creatinine and IL-6 levels ( $r=0.511, \mathrm{p}<0.001$, and $\mathrm{r}=0.338, \mathrm{p}=0.012$, respectively), and with blood leukocyte count $(\mathrm{r}=0.421, \mathrm{p}=0.002)$.

Eighteen out of 37 (49\%) men presented with a low Testo level during the acute phase of NE. Fifteen of them had a coincident serum LH level within the reference range, and three had an increased LH level. In addition, $5(14 \%)$ men had an elevated LH concentration together with a Testo level within the reference range. None of the eight male patients with acute primary hypogonadism (elevated LH) complained of testicular pain. The minimum Testo concentration correlated inversely with age and leukocytosis $(r=-0.341, p=0.039$, and $r=-$ 0.493, $\mathrm{p}=0.002$, respectively), and with maximum creatinine, IL-6, CRP and PRL levels ( $\mathrm{r}=-0.437, \mathrm{p}=0.007 ; \mathrm{r}=-$ $0.411, \mathrm{p}=0.011 ; \mathrm{r}=-0.352, \mathrm{p}=0.032, \mathrm{r}=-363, \mathrm{p}=0.027$, respectively), but not with body mass index $(\mathrm{BMI})(\mathrm{r}=-$ $0.009, \mathrm{p}=0.957)$. Three out of six premenopausal women (aged 16, 21 and 37 years) presented with low E2 and FSH levels during the acute phase of NE (E2 range 0.04-0.05 nmol/1, and FSH range 0.08-0.8 U/l).

Two patients had a low serum fT4 level together with a low-normal TSH level during the acute phase. Five out of $54(9 \%)$ patients presented with an increased serum TSH level, together with fT4 within the lownormal range; one of them had a previously diagnosed primary hypothyroidism, and she used L-thyroxine substitution throughout the study. Serum fT4 and TSH levels measured during acute NE did not correlate with age, BMI, plasma creatinine, CRP, or cytokine levels (data not shown).

Altogether 30 out of $54(56 \%)$ patients had abnormalities of the gonadal and/or thyroid axis during the acute phase of NE. Central hormonal defects were found in 19 patients, while 13 patients had a primary 
deficit. As shown in Table 2, the patients with central hormonal deficiencies had a higher plasma creatinine concentration, and blood leukocyte count than the patients with normal hormone levels.

There were no differences in the clinical picture or basic laboratory findings during acute NE between the patients with primary hormonal deficiencies and those with normal hormone levels (data not shown). Neither did the cytokine levels or HLA-B8, -DR3 and -B27 alleles predict the acute primary hormone deficits.

\section{Hormonal deficiencies one to ten years after NE}

During a median follow-up of 5 years, 9 out of $54(17 \%)$ NE patients presented with chronic, overt hormonal deficits. Table 3 shows the serial plasma hormone levels of these patients. The clinical diagnoses of overt hormonal deficiencies were based both on the hormone measurements and on the clinical signs and symptoms of the patients.

One of the 2 patients with hormone levels suggestive of combined pituitary hormone defects, a 43year old male patient (patient 1, table 3), presented with low testosterone levels and declining fT4 levels within the low reference range during acute NE, as well as after 3 and 12 months (Testo 7.1-7.8-7.6 nmol/1, LH 2.8-2.1$1.8 \mathrm{U} / 1$, fT4 11.9-10.6-10.4 pmol/1, and TSH 2.8-3.8-1.9 mU/1, respectively). He died for an unknown reason soon after his 1-year follow-up visit. The hormone levels, indicating central hypogonadism and possible hypothyroidism, were analyzed only after his death. The overt hormonal deficiencies of the other patients, as well, had gone unnoticed until the patients were invited to the additional visit in 2008 . Only one female patient had been started on L-thyroxine, due to overt hypothyroidism diagnosed 9 years after the acute NE (patient 8 , table 3).

There were no differences in the age or gender distribution, clinical picture or basic laboratory findings during acute NE between those 9 patients who presented with chronic hormone deficiencies after NE and those with normal hormone levels (Table 4). None of the 3 patients who were hypotensive on admission developed chronic hormonal deficiencies. The prevalence of HLA-B8, -DR3 and -B27 alleles did not differ between the groups (data not shown).

Imaging studies on the additional visit in 2008

Thyroid ultrasound examination showed diffuse or patchy hypoechogenicity, pertinent with thyroiditis, in the five patients with primary hypothyroidism, while TPOAb were measurable in only $2 \mathrm{of}$ them. A sellar MRI scan was performed during the additional visit in 2008 in two men whose symptoms and hormone 
levels suggested central hormonal defects. One had an apparent GH deficiency (patient 5, table 3), and the other was a 41-year-old patient who developed a marked secondary hypogonadism and a probable secondary hypothyroidism (patient 2, table 3). The MRI scans showed no pathology of the hypothalamic-pituitary region in either of them.

\section{Discussion}

To our knowledge, this is the first study on hormonal alterations occurring during and after NE. Serum cortisol and PRL levels were higher and serum Testo concentrations lower during acute NE compared to the corresponding values after 3 months. These acute hormonal alterations were related to the severity of acute renal insufficiency and inflammation. After one to ten years, surprisingly many patients suffered from chronic hormonal deficits of either central or peripheral origin. The chronic defects could not be predicted by renal insufficiency, degree of inflammation, or other markers of the clinical severity of acute NE, or by the host genetic factors studied.

Approximately half of the men and premenopausal women presented with low serum gonadal hormone levels during the acute phase of NE. Serum Testo levels in general increased during a 3-month followup, while concomitant LH levels remained stable, indicating that the acute hypogonadism was transient and of central origin in most cases. The degree of hypothalamic-pituitary-gonadal axis suppression, as well as the increase in plasma cortisol production, are known to be related to the severity of acute illness [22, 23]. Also in our patients with acute NE, low Testo levels and high cortisol and PRL levels were related to the degree of inflammation and the severity of acute renal failure. As the kidneys are involved in the elimination of PRL and corticosteroids $[24,25]$, the acute impairment of renal function during NE may have resulted in diminished clearance of PRL and cortisol, contributing to their increased serum levels.

We also found eight male patients with acute primary hypogonadism during PUUV infection. Three out of these 8 acute testicular failures developed into chronic, compensated ones, i.e., Testo levels remained within the normal range, while LH levels were chronically elevated. In addition, two cases of chronic, compensated hypogonadism developed during the follow-up, without testicular dysfunction during the acute NE. There are no previous reports of clinical orchitis or primary hypogonadism in hantaviral diseases. However, the possibility remains that PUUV-infection may have contributed to the pathogenesis of acute and chronic primary hypogonadism, which were over-represented $[26,27]$ in this relatively young group of patients (median age in males 39 years, the youngest patient with chronic hypogonadism 30 years). 
Primary hypothyroidism was remarkably frequent in our patients with NE. Two patients had been

diagnosed with hypothyroidism prior to NE, and 5 more diagnoses of primary hypothyroidism were made during the follow-up. The overall prevalence of primary hypothyroidism thus mounted up to $24 \%$ in the female patients and $8 \%$ in the males, which are about three-fold prevalences compared to those recently reported for similar age groups in the general population [28-30]. All of the patients diagnosed with primary hypothyroidism in the present study showed a hypoechogenic structure of the thyroid on ultrasound examination, suggesting chronic thyroiditis [31,32]. TPOAb were present in only 2 of the 5 "new" cases of hypothyroidism, which may indicate that in the other 3 cases, the thyroiditis was not of autoimmune origin, but was possibly induced by the PUUV infection. The primary thyroid, or gonadal, defects did not relate to age, gender, or the degree of renal insufficiency or inflammation during acute NE. A high level of vigilance for possible signs of thyroid or gonadal dysfunction seems warranted in patients with a history of previous NE.

Seventeen percent of the present patients were diagnosed with a chronic, overt hormonal deficit. In a recent retrospective Serbian study the prevalence of any endocrine deficiency 2 years after HFRS was $18 \%$ [14]. It is noteworthy that the patients in the Serbian study had a more severe HFRS than our patients. In the present study, only three patients needed dialysis treatment, while $57 \%$ of the Serbian patients were dialyzed. PUUV and DOBV coexist in the Balkan area, and induce HFRS with significant differences in severity [33, 34]. DOBV-infected patients have more frequently suffered from acute renal failure requiring dialysis treatment, shock, severe thrombocytopenia, and hemorrhagic complications than patients with PUUV [33, 34]. In the present study, chronic hormonal defects could not be predicted by the severity of acute NE. Hence, it is worth noticing that chronic hormonal deficits might occur even after a relatively mild hantaviral infection.

Previous case reports of severe HFRS have described hypophyseal hemorrhage and panhypopituitarism associated with PUUV and HTNV infections [7-11, 35-38]. The development of hypophyseal hemorrhage and subsequent panhypopituitarism has varied from acute to subacute. The mechanisms of pituitary hemorrhage are unknown, although hypovolemic shock and thrombocytopenia may contribute to the pathogenesis. In the present patients, thrombocytopenia or hypotension during acute NE did not correlate with either acute-phase or long-term hormonal abnormalities. Neither were there any MRI findings pertinent with previous hypophyseal or hypothalamic hemorrhage in the patients with central hormonal defects. It is likely that the secondary hormone deficiencies found in the present series of NE patients developed by mechanisms other than an acute hemorrhagic disruption of the pituitary. 
Headache, vertigo, visual disturbances, and other signs of central nervous system involvement occur

frequently in NE [2, 3, 39, 40], and cases of PUUV-induced meningoencephalitis have been reported [2, 3, 41, 42]. Presence of PUUV RNA in cerebrospinal fluid in a patient with acute NE has been confirmed [43]. It has recently been shown that infections of the central nervous system may cause transient or permanent hypothalamic and/or pituitary dysfunction [44]. Viral meningoencephalitis or hypophysitis may also have contributed to the central hormone defects frequently found in our patients.

An important feature in hantaviral infections is a universally increased capillary permeability, causing tissue edema and hypotension [1]. Immunological factors including overproduction of pro-inflammatory cytokines during acute infection are probably involved in the pathogenesis, and might result in immune-mediated damage to the endothelial cells [15]. The endothelial damage and increased vascular permeability may have been involved in the pathogenesis of central and peripheral hormonal defects of the NE patients. A tight interaction between the immune and endocrine systems, mainly through the HPA axis $[16,17]$, is also likely to play a central role in the hormonal alterations, at least during acute NE.

Our study has some limitations. First, due to the retrospective nature of the hormonal analyses we did not have complete data on the possible signs and symptoms related to hormonal alterations during and after NE. This may have resulted in underestimation of the hormonal sequelae of $\mathrm{NE}$, as milder forms of pituitary failure cannot be diagnosed by means of basal hormone levels alone. Stimulatory tests of the GH-IGF-1 axis or the HPA axis could have revealed more subtle hormonal defects, over and above the prevalence of overt hormonal failures reported here. In addition, it would have been valuable to include patients with other viral infections as controls. These limitations, however, should be set against the strengths of investigating a prospectively gathered group of consecutive patients both during the acute phase of NE and repeatedly during the long-term follow-up. The findings of the present study give rise to prospective, controlled studies to verify the prevalence of hormonal defects after hantaviral diseases, and to clarify the pathogenesis of these hormonal alterations.

In summary, hormonal alterations were common during acute NE, and the acute hormone deficits of central origin correlated with the clinical severity of NE. Chronic hormonal defects, however, could not be predicted by the severity of acute NE, and chronic deficits emerged even after a relatively mild course of NE. Patients with a history of NE should be readily investigated for hormonal deficiencies, in view of the high prevalence of chronic central and peripheral hormone defects in these patients. 
Acknowledgements: There is no conflict of interest and nothing to declare. This work was supported by the

Competitive Research Funding of the Pirkanmaa Hospital District, by the Finnish Kidney Foundation and by the European Commission Project "Diagnostics and control of rodent-borne viral zoonoses in Europe" (QLK2-CT2002-01358). We thank Jukka Partanen for the analyses of HLA alleles, and Esko Väyrynen for language revision. The skilful technical assistance of Heidi Hällström, Katriina Ylinikkilä and Mirja Ikonen is greatly appreciated. 


\section{References}

1. Vapalahti O, Mustonen J, Lundkvist Å, Henttonen H, Plyusnin A, Vaheri A (2003) Hantavirus infections in Europe. Lancet Infect Dis 3 (10):653-661

2. Lähdevirta J (1971) Nephropathia epidemica in Finland. A clinical histological and epidemiological study. Ann Clin Res 3:1-54

3. Mustonen J, Brummer-Korvenkontio M, Hedman K, Pasternack A, Pietilä K, Vaheri A (1994) Nephropathia epidemica in Finland: a retrospective study of 126 cases. Scand J Infect Dis 26 (1):7-13

4. Settergren B, Juto P, Trollfors B, Wadell G, Norrby SR (1989) Clinical characteristics of nephropathia epidemica in Sweden: prospective study of 74 cases. Rev Infect Dis 11 (6):921-927

5. Mustonen J, Partanen J, Kanerva M, Pietilä K, Vapalahti O, Pasternack A, Vaheri A (1996) Genetic susceptibility to severe course of nephropathia epidemica caused by Puumala hantavirus. Kidney Int 49 (1):217221

6. Mustonen J, Partanen J, Kanerva M, Pietilä K, Vapalahti O, Pasternack A, Vaheri A (1998) Association of HLA B27 with benign clinical course of nephropathia epidemica caused by Puumala hantavirus. Scand J Immunol 47 (3):277-279

7. Forslund T, Saltevo J, Anttinen J, Auvinen S, Brummer-Korvenkontio M, Korhonen A, Poutiainen M (1992) Complications of nephropathia epidemica: three cases. J Intern Med 232 (1):87-90

8. Hautala T, Sironen T, Vapalahti O, Pääkkö E, Särkioja T, Salmela PI, Vaheri A, Plyusnin A, Kauma H (2002) Hypophyseal hemorrhage and panhypopituitarism during Puumala Virus Infection: Magnetic Resonance Imaging and detection of viral antigen in the hypophysis. Clin Infect Dis 35 (1):96-101

9. Sane T, Färkkilä M (2002) Hypopituitarism and hepatitis as complications of nephropathia epidemica.

Duodecim 118 (5):457-461

10. Settergren B, Boman J, Linderholm M, Wiström J, Hagg E, Arvidsson PA (1992) A case of nephropathia epidemica associated with panhypopituitarism and nephrotic syndrome. Nephron 61 (2):234-235

11. Valtonen M, Kauppila M, Kotilainen P, Lähdevirta J, Svartbäck CM, Kosunen O, Nurminen J, Sarkkinen H, Brummer-Korvenkontio M (1995) Four fatal cases of nephropathia epidemica. Scand J Infect Dis 27 (5):515-517

12. Hullinghorst RL, Steer A (1953) Pathology of epidemic hemorrhagic fever. Ann Intern Med 38 (1):77-101 
13. Lukes RJ (1954) The pathology of thirty-nine fatal cases of epidemic hemorrhagic fever. Am J Med 16

(5):639-650

14. Stojanovic M, Pekic S, Cvijovic G, Miljic D, Doknic M, Nikolic-Djurovic M, Micic D, Hrvacevic R, Nesic V, Popovic V (2008) High risk of hypopituitarism in patients who recovered from hemorrhagic fever with renal syndrome. J Clin Endocrinol Metab 93 (7):2722-2728

15. Kanerva M, Mustonen J, Vaheri A (1998) Pathogenesis of Puumala and other hantavirus infections. Rev Med Virol 8 (2):67-86

16. Imura H, Fukata J (1994) Endocrine-paracrine interaction in communication between the immune and endocrine systems. Activation of the hypothalamic-pituitary-adrenal axis in inflammation. Eur J Endocrinol 130 (1):32-37

17. Turnbull AV, Rivier CL (1999) Regulation of the hypothalamic-pituitary-adrenal axis by cytokines: actions and mechanisms of action. Physiol Rev 79 (1):1-71

18. Vapalahti O, Lundkvist Å, Kallio-Kokko H, Paukku K, Julkunen I, Lankinen H, Vaheri A (1996) Antigenic properties and diagnostic potential of Puumala virus nucleocapsid protein expressed in insect cells. J Clin Microbiol 34 (1):119-125

19. Sjölander KB, Elgh F, Kallio-Kokko H, Vapalahti O, Hägglund M, Palmcrantz V, Juto P, Vaheri A, Niklasson B, Lundkvist Å (1997) Evaluation of serological methods for diagnosis of Puumala hantavirus infection (nephropathia epidemica). J Clin Microbiol 35 (12):3264-3268

20. Westman P, Kuismin T, Partanen J, Koskimies S (1993) An HLA-DR typing protocol using group-specific PCR-amplification followed by restriction enzyme digests. Eur J Immunogenet 20 (2):103-109

21. AACE Guidelines (2002) American Association of Clinical Endocrinologists Medical Guidelines for Clinical Practice for the Evaluation and Treatment of Hyperthyroidism and Hypothyroidism. Endocrine Practice 8 (6):457-469

22. Jurney TH, Cockrell JLJ, Lindberg JS, Lamiell JM, Wade CE (1987) Spectrum of serum cortisol response to ACTH in ICU patients. Correlation with degree of illness and mortality. Chest 92 (2):292-295

23. Spratt DI, Cox P, Orav J, Moloney J, Bigos T (1993) Reproductive axis suppression in acute illness is related to disease severity. J Clin Endocrinol Metab 76 (6):1548-1554 
24. Bauer AG, Wilson JH, Lamberts SW (1980) The kidney is the main site of prolactin elimination in patients with liver disease. J Clin Endocrinol Metab 51 (1):70-73

25. Whitworth JA, Stewart PM, Burt D, Atherden SM, Edwards CR (1989) The kidney is the major site of cortisone production in man. Clin Endocrinol (Oxf) 31 (3):355-361

26. Gray A, Feldman HA, McKinlay JB, Longcope C (1991) Age, disease, and changing sex hormone levels in middle-aged men: results of the Massachusetts Male Aging Study. J Clin Endocrinol Metab 73 (5):1016-1025

27. Härkönen K, Huhtaniemi I, Mäkinen J, Hubler D, Irjala K, Koskenvuo M, Oettel M, Raitakari O, Saad F, Pollänen P (2003) The polymorphic androgen receptor gene CAG repeat, pituitary-testicular function and andropausal symptoms in ageing men. Int J Androl 26 (3):187-194

28. Bjoro T, Holmen J, Kruger O, Midthjell K, Hunstad K, Schreiner T, Sandnes L, Brochmann H (2000) Prevalence of thyroid disease, thyroid dysfunction and thyroid peroxidase antibodies in a large, unselected population. The Health Study of Nord-Trondelag (HUNT). Eur J Endocrinol 143 (5):639-647

29. Hollowell JG, Staehling NW, Flanders WD, Hannon WH, Gunter EW, Spencer CA, Braverman LE (2002) Serum TSH, T(4), and thyroid antibodies in the United States population (1988 to 1994): National Health and Nutrition Examination Survey (NHANES III). J Clin Endocrinol Metab 87 (2):489-499

30. Vanderpump M (2005) The epidemiology of thyroid diseases. JB Lippincott-Raven, Philadelphia, p 398-406 31. Hegedus L (2001) Thyroid ultrasound. Endocrinol Metab Clin North Am 30 (2):339-360

32. McGahan JP, Goldberg BB (2008) Diagnostic ultrasound. Informa Healthcare, New York-London 33. Avsic-Zupanc T, Petrovec M, Furlan P, Kaps R, Elgh F, Lundkvist Å (1999) Hemorrhagic fever with renal syndrome in the Dolenjska region of Slovenia--a 10-year survey. Clin Infect Dis 28 (4):860-865

34. Markotic A, Nichol ST, Kuzman I, Sanchez AJ, Ksiazek TG, Gagro A, Rabatic S, Zgorelec R, Avsic-Zupanc T, Beus I, Dekaris D (2002) Characteristics of Puumala and Dobrava infections in Croatia. J Med Virol 66 (4):542-551

35. Kim NH, Cho JG, Ahn YK, Lee SU, Kim KH, Cho JH, Kim HG, Kim W, Jeong MH, Park JC, Kang JC (2001) A case of torsade de pointes associated with hypopituitarism due to hemorrhagic fever with renal syndrome. J Korean Med Sci 16 (3):355-359 
36. Park JE, Pyo HJ (1996) Delayed onset of diuresis in a patient with acute renal failure due to hemorrhagic fever with renal syndrome who also developed anterior hypopituitarism. Clin Nephrol 46 (2):141-145

37. Pekic S, Cvijovic G, Stojanovic M, Kendereski A, Micic D, Popovic V (2005) Hypopituitarism as a late complication of hemorrhagic fever. Endocrine $26(2): 79-82$

38. Suh DC, Park JS, Park SK, Lee HK, Chang KH (1995) Pituitary hemorrhage as a complication of hantaviral disease. AJNR Am J Neuroradiol 16 (1):175-178

39. Ahlm C, Linden C, Linderholm M, Alexeyev OA, Billheden J, Elgh F, Fagerlund M, Zetterlund B, Settergren B (1998) Central nervous system and ophthalmic involvement in nephropathia epidemica (European type of haemorrhagic fever with renal syndrome). J Infect 36 (2):149-155

40. Alexeyev OA, Morozov VG (1995) Neurological manifestations of hemorrhagic fever with renal syndrome caused by Puumala virus: review of 811 cases. Clin Infect Dis 20 (2):255-258

41. Bergmann F, Krone B, Bleich S, Prange H, Paulus W (2002) Encephalitis due to a hantavirus infection. J Infect $45(1): 58-59$

42. Launes J, Hautanen A (1988) Nephropathia epidemica encephalitis. Acta Neurol Scand 78 (3):234-235

43. Mähönen SM, Sironen T, Vapalahti O, Paakko E, Hautala N, Ilonen J, Glumoff V, Vainio O, Kauma H, Vaheri A, Plyusnin A, Hautala T (2007) Puumala virus RNA in cerebrospinal fluid in a patient with uncomplicated nephropathia epidemica. J Clin Virol 40 (3):248-251

44. Schaefer S, Boegershausen N, Meyer S, Ivan D, Schepelmann K, Kann PH (2008) Hypothalamic-pituitary insufficiency following infectious diseases of the central nervous system. Eur J Endocrinol 158 (1):3-9 
Table 1. Serum hormone levels during acute NE, and after 3 months.

\begin{tabular}{|c|c|c|c|c|c|}
\hline & Acute $\mathrm{pl}$ & $\sec ^{a}$ & At $3 \mathrm{mo}$ & & $\mathrm{p}$ \\
\hline & Median & Range & Median & Range & \\
\hline All patients $(\mathrm{n}=54)$ : & & & & & \\
\hline Cortisol (nmol/1) & 520 & $267-1157$ & 361 & $163-606$ & $<0.001 *$ \\
\hline Prolactin $(\mathrm{mU} / \mathrm{l})^{\mathrm{b}}$ & 266 & $32-1364$ & 131 & $46-550$ & $<0.001 *$ \\
\hline Thyrotropin (mU/l) & 1.9 & $0.1-9.0$ & 1.7 & $0.02-7.6$ & $0.011 *$ \\
\hline Free thyroxine $(\mathrm{pmol} / \mathrm{l})$ & 12.2 & $7.5-18.1$ & 12.8 & $10.1-17.4$ & 0.526 \\
\hline Males $(n=37)$ : & & & & & \\
\hline Testosterone (nmol/l) & 9.9 & $1.1-27.0$ & 17.3 & $7.8-25.4$ & $<0.001 *$ \\
\hline Luteinizing hormone (U/1) & 4.0 & $0.9-18.0$ & 3.6 & $2.0-7.9$ & 0.399 \\
\hline Females $(n=16)^{b}$ : & & & & & \\
\hline Follicle-stimulating hormone (U/l) & 4.7 & $0.6-40.4$ & 23.7 & $3.0-73.2$ & $0.001 *$ \\
\hline Estradiol (nmol/l) & 0.07 & $0.02-0.42$ & 0.11 & $0.04-0.49$ & 0.263 \\
\hline
\end{tabular}

${ }^{a}$ the highest or the lowest serum concentration of each hormone measured during hospitalization, as appropriate. ${ }^{b}$ One patient was breast-feeding during acute NE and her E2, FSH and PRL values were excluded from the analyses (see Subjects and Methods).*Statistically significant difference between hormone levels measured in the acute phase and 3 months later (Wilcoxon signed-rank test). 
Table 2. Clinical and laboratory findings of the 19 patients diagnosed with central hormonal defects during the acute phase of NE, compared to those of the 23 patients with normal hormone levels.

\begin{tabular}{|c|c|c|c|c|c|}
\hline \multirow[t]{2}{*}{ Finding } & \multicolumn{2}{|c|}{$\begin{array}{l}\text { Central hormonal defects } \\
n=19\end{array}$} & \multicolumn{2}{|c|}{$\begin{array}{l}\text { Normal hormone levels } \\
n=23\end{array}$} & \multirow[t]{2}{*}{$\mathrm{p}$} \\
\hline & Median & Range & Median & Range & \\
\hline Age (years) & 41 & $17-62$ & 41 & $24-70$ & 0.909 \\
\hline Gender $(\mathrm{M} / \mathrm{F})$ & $15 / 4$ & & $13 / 10$ & & 0.125 \\
\hline Body mass index $\left(\mathrm{kg} / \mathrm{m}^{2}\right)$ & 25 & $19-37$ & 26 & $19-42$ & 0.456 \\
\hline Creatinine max $(\mu \mathrm{mol} / \mathrm{l})$ & 368 & $79-749$ & 208 & $76-878$ & $0.029 *$ \\
\hline Leukocytes $\max \left(10^{9} / 1\right)$ & 13.4 & $4.4-22.8$ & 9.2 & $6.7-23.4$ & $0.033^{*}$ \\
\hline Platelets $\min \left(10^{9} / 1\right)$ & 62 & $13-127$ & 53 & $18-136$ & 0.869 \\
\hline C-reactive protein $\max (\mathrm{mg} / \mathrm{l})$ & 78 & $22-213$ & 67 & $27-136$ & 0.791 \\
\hline Plasma IL-6 max (pg/ml) & 19.6 & $5.9-40.7$ & 13.5 & $3.3-59.1$ & 0.052 \\
\hline Plasma TNF- $\alpha$ max (pg/ml) & 3.4 & $1.4-26.9$ & 3.8 & $1.4-37.4$ & 0.693 \\
\hline Proteinuria max (g/day) & 1.8 & $0.2-9.5$ & 2.0 & $0.3-17.8$ & 0.990 \\
\hline Duration of hospital stay (days) & 8 & $5-13$ & 7 & $3-11$ & 0.134 \\
\hline
\end{tabular}

*Statistically significant difference between patients with acute central hormone deficits and those with normal hormone levels. The Mann-Whitney U-test was used for continuous variables; Pearson chi-square test was used for gender. Abbreviations: $\mathrm{M}=$ male, $\mathrm{F}=$ female, $\mathrm{IL}=$ interleukin, $\mathrm{TNF}-\alpha=$ tumor necrosis factor alpha, $\min =$ minimum, $\max =$ maximum . 
Table 3. Serial plasma hormone levels of 9 NE patients who presented with chronic, overt hormonal deficits during a median follow-up of 5 years. The hormone levels presented in the table were measured during the acute phase of NE (first value in each series) and on the follow-up visits 1 to 10 years later ( $2^{\text {nd }}$ and $3^{\text {rd }}$ value of each series). Abnormal values are printed in bold.

\begin{tabular}{|c|c|c|c|c|c|c|c|}
\hline Patient & $\begin{array}{l}\text { Gender / age } \\
\text { during acute } \\
\text { NE (years) }\end{array}$ & $\begin{array}{l}\text { Duration } \\
\text { of follow- } \\
\text { up (years) }\end{array}$ & $\begin{array}{l}\text { Testosterone in males } \\
\text { and E2 in females } \\
(\mathrm{nmol} / \mathrm{l})\end{array}$ & $\begin{array}{l}\text { LH in males and } \\
\text { FSH in females (U/l) }\end{array}$ & fT4 (pmol/l) & TSH (mU/l) & $\begin{array}{l}\text { Clinical } \\
\text { diagnosis }\end{array}$ \\
\hline 1 & $\mathrm{M} / 43$ & $1 *$ & $7.1-7.6$ & $2.8-1.8$ & $11.9-10.4$ & $2.8-1.9$ & $\mathrm{CHG}$ \\
\hline 2 & $\mathrm{M} / 41$ & 9 & $11.6-8.1-7.4$ & $1.6-2.0-2.6$ & $12.5-10.4-10.4$ & $1.2-1.0-0.9$ & $\mathrm{CHG}$ \\
\hline 3 & $\mathrm{M} / 59$ & 5 & $\mathbf{1 . 9}-11.5-\mathbf{7 . 6}$ & $1.7-3.6-2.3$ & $11.0-11.4-12.1$ & $1.3-1.7-1.5$ & $\mathrm{CHG}$ \\
\hline 4 & $\mathrm{M} / 52$ & $1 *$ & $7.9-9.8$ & $2.5-2.8$ & $14.5-13.3$ & $2.3-1.5$ & $\mathrm{CHG}$ \\
\hline 5 & $\mathrm{M} / 42$ & 9 & $11.3-15.7-21.9$ & $18.0-5.5-6.8$ & $11.2-13.9-13.4$ & $1.9-\mathbf{4 . 3}-\mathbf{5 . 0}$ & PHT ** \\
\hline 6 & $\mathrm{M} / 58$ & 9 & $12.5-15.3-10.7$ & $6.9-6.7-9.2$ & $14.0-12.8-12.0$ & $3.7-4.3-5.7$ & PHT \\
\hline 7 & $\mathrm{M} / 60$ & 7 & $\mathbf{1 . 1}-19.2-21.1$ & $2.8-5.0-4.0$ & $9.4-10.9-11.7$ & $1.7-5.8-9.9$ & PHT \\
\hline 8 & $\mathrm{~F} / 17$ & 9 & $0.05-0.07-<0.06$ & $0.6-2.8-0.4$ & $16.2-11.5-12.5$ & $3.5-2.7-6.6 * * *$ & CHG, PHT \\
\hline 9 & $\mathrm{~F} / 47$ & 9 & $0.05-<0.02-<0.06$ & $2.6-41.5-39.8$ & $9.5-9.9-9.4$ & $9.0-11.5-16.1$ & PHT \\
\hline
\end{tabular}

CHG=central hypogonadism, PHT=primary hypothyroidism, E2=estradiol, LH=luteinizing hormone, FSH=follicle-stimulating hormone, fT4=free thyroxine, TSH=thyrotropin

* only the hormone levels measured during acute NE and 1 year later are shown for the two patients, whose follow-up ended at the 1-year visit

** and a possible growth hormone (GH) deficiency: an undetectable GH level and insulin-like growth factor-1 6,5 nmol/1 (reference range 10-29 nmol/l)

*** on L-thyroxine treatment

The reference ranges were 10.4-34.6 nmol/l for testosterone, and 0.7-6.7 U/l for LH in men. An E2 level below 0.1 nmol/l was considered hypogonadal in premenopausal women, as the phase of menstrual cycle was not known. Peri- and postmenopausal women were not analyzed for gonadal defects, as they were hypogonadal by definition. The reference range for fT4 was 9.0-19.0 pmol/1, and for TSH 0.4-4.0 mU/1. 
Table 4. Clinical and laboratory findings during the acute phase of NE in the 9 patients who developed chronic hormonal defects after NE, compared to those in the 45 patients whose hormone levels remained normal during the follow-up.

\begin{tabular}{|c|c|c|c|c|c|}
\hline \multirow[t]{2}{*}{ Finding } & \multicolumn{2}{|c|}{$\begin{array}{l}\text { Chronic hormonal defects } \\
n=9\end{array}$} & \multicolumn{2}{|c|}{$\begin{array}{l}\text { No chronic defects } \\
n=45\end{array}$} & \multirow[t]{2}{*}{$\mathrm{p}$} \\
\hline & Median & Range & Median & Range & \\
\hline Age (years) & 47 & $17-60$ & 39 & $15-70$ & 0.194 \\
\hline Gender (M/F) & $7 / 2$ & & $30 / 15$ & & 0.512 \\
\hline Body mass index $\left(\mathrm{kg} / \mathrm{m}^{2}\right)$ & 26 & $21-37$ & 25 & $19-42$ & 0.347 \\
\hline Creatinine $\max (\mu \mathrm{mol} / \mathrm{l})$ & 380 & $98-725$ & 213 & $76-878$ & 0.190 \\
\hline Leukocytes $\max \left(10^{9} / 1\right)$ & 11.2 & $5.7-20.4$ & 10.3 & $4.4-23.4$ & 0.926 \\
\hline Platelets $\min \left(10^{9} / 1\right)$ & 54 & $17-139$ & 62 & $3-136$ & 0.898 \\
\hline C-reactive protein $\max (\mathrm{mg} / \mathrm{l})$ & 72 & $25-213$ & 67 & $20-136$ & 0.423 \\
\hline Plasma IL-6 max (pg/ml) & 19.9 & $5.0-43.0$ & 14.2 & $3.3-59.1$ & 0.102 \\
\hline Plasma TNF- $\alpha \max (\mathrm{pg} / \mathrm{ml})$ & 2.8 & $1.4-8.7$ & 3.7 & $1.4-37.4$ & 0.267 \\
\hline Proteinuria max (g/day) & 0.9 & $0.3-3.9$ & 2.0 & $0.1-17.8$ & 0.114 \\
\hline Duration of hospital stay (days) & 6 & $5-13$ & 7 & $3-12$ & 0.833 \\
\hline
\end{tabular}

The Mann-Whitney U-test was used for continuous variables; Pearson chi-square test was used for gender. Abbreviations: $\mathrm{M}=$ male, $\mathrm{F}=$ female, $\mathrm{IL}=$ interleukin, $\mathrm{TNF}-\alpha=$ tumor necrosis factor alpha, $\min =$ minimum, $\max =$ maximum 


\section{Legend to Figure 1.}

1

Figure shows serum testosterone (A) and luteinizing hormone (LH) (B) levels measured in 37 men during acute $\mathrm{NE}$ and after 3 months. Testosterone levels were below the reference range in half of the men during acute NE, while LH levels were within the reference range in the majority, indicating that the hypogonadism was mostly of central origin. The reference ranges were 10.4-34.6 nmol/l for testosterone (vertical line showing lower reference limit) and 0.7-6.7 U/l for LH (vertical line showing higher reference limit). 
A

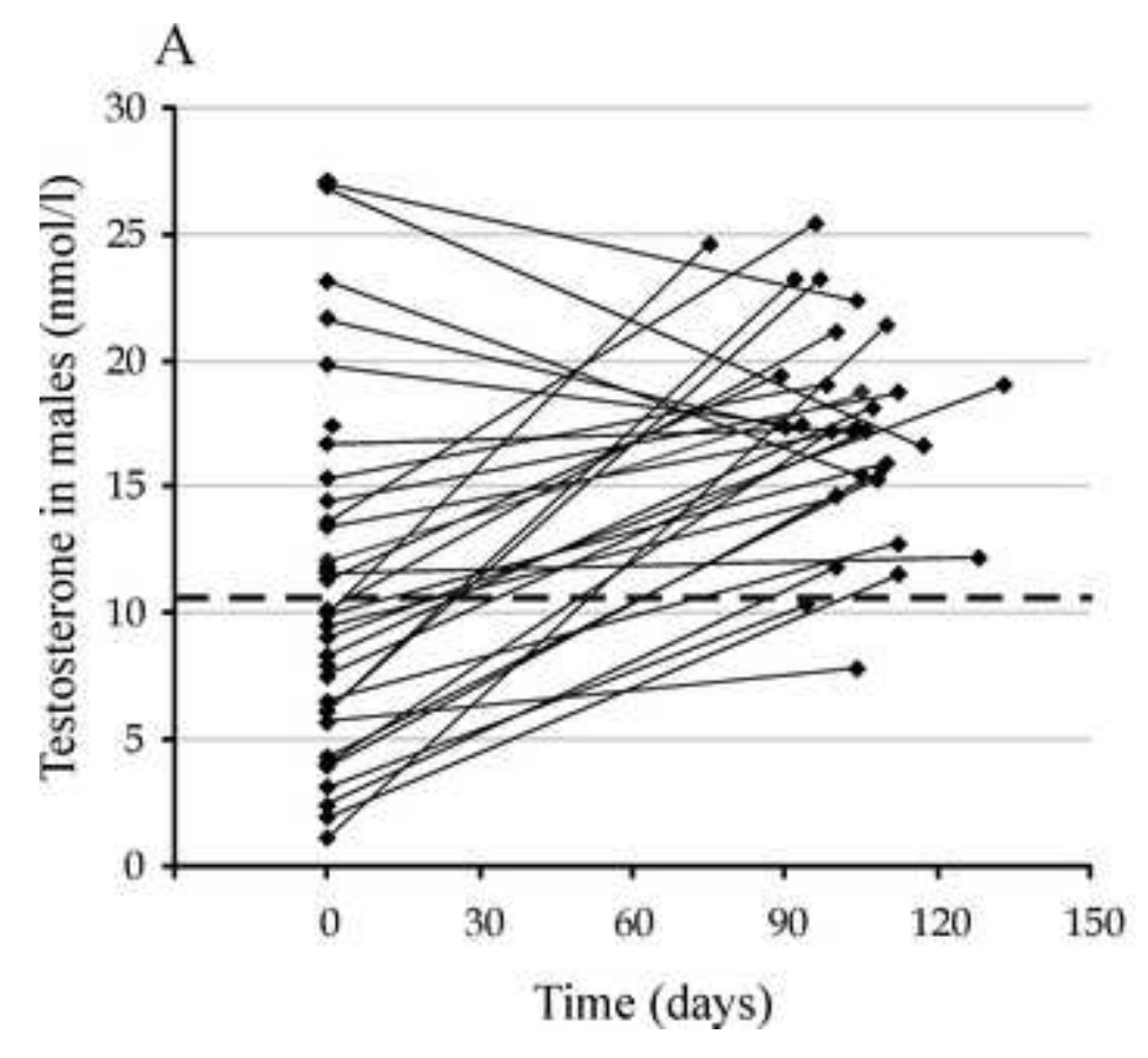

B

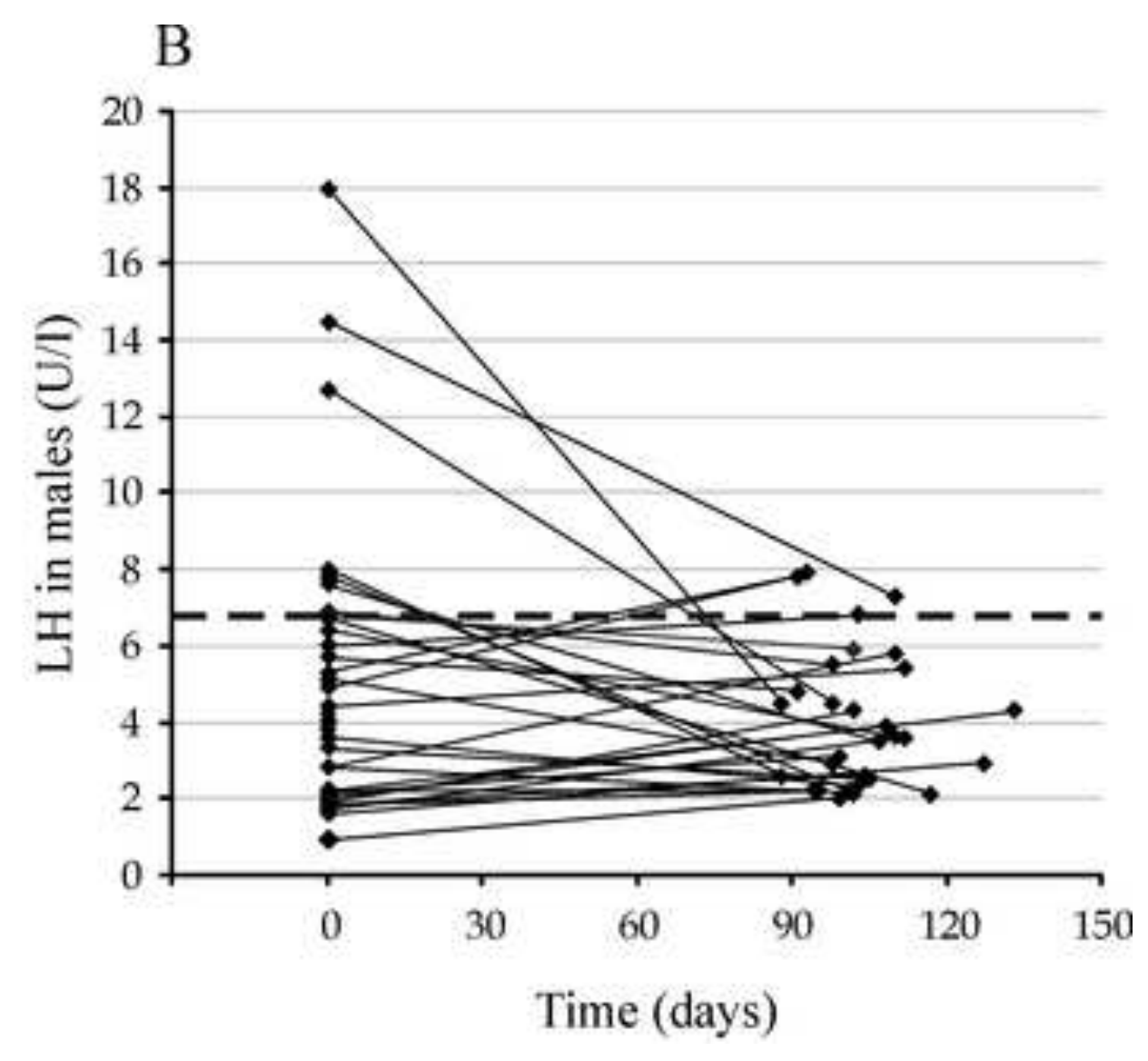




\section{Ms. No. EJCMID-D-10-00050}

\section{Hormonal Deficiencies During and After Puumala Hantavirus Infection}

Point-by-point responses to the comments by Reviewer 1

\section{Major points:}

A. According to the reviewer's advice, we have now added two new tables (Tables 3 and 4) to clarify the presentation of the observations. Table 3 shows the clinical diagnoses and serial plasma hormone levels in those 9 NE patients who presented with chronic, overt hormonal deficits. In Table 4, we show the acute-phase clinical and laboratory findings of the 9 patients, who developed chronic hormonal defects after NE, compared to those 45 patients, whose hormone levels remained normal during the follow-up. Since the clinical diagnoses of hormonal deficiencies are now shown in Table 3 (in the revised version), we have omitted the corresponding text from Results, Hormonal deficiencies: "Of these 9 patients, 2 were diagnosed with isolated central hypogonadism, 2 had multiple pituitary hormone deficiencies, 2 had primary hypothyroidism only, one had primary hypothyroidism and primary hypogonadism, one was diagnosed with isolated central hypogonadism and peripheral hypothyroidism, and one with primary hypothyroidism and a possible GH deficiency (undetectable GH level and IGF-1 6.5 nmol/l; reference range 10-29 nmol/l)." In order to further clarify the results, we have also referred to the patients described in Table 3 (e.g. "patient 1, table 3") in the revised text: Results, page 8, Hormonal deficiencies, lines 6 and 12, as well as in Results, Imaging studies, page 9, the first and the third line). We have omitted the following text from Results, Imaging studies: "Testo 11.6-10.8-8.1-7.4 nmol/l, LH 1.6-1.4-2.0-2.6 U/l, fT4 12.5-11.8-10.4-10.4 pmoll, and TSH 1.2-1.1-1.0-0.9 mU/l, measured in the acute phase, and after 1 year, 5 and 9 years, respectively", since the same values are now shown in Table 3 (patient 2) of the revised version.

$B$. The reviewer correctly points out that in the original manuscript (Results, the second paragraph) the expression "Table 1 shows that serum median cortisol and PRL levels increased and Testo concentration decreased during the acute phase of NE" is misleading. We have now revised the sentence in page 7, the second line, as follows: "Table 1 shows that serum median cortisol and PRL levels were higher and Testo concentrations lower during the acute phase of NE”. 
Accordingly, we have revised the Discussion, the second line, as follows: "Serum cortisol and PRL levels were higher and serum Testo concentrations lower during acute NE compared to the corresponding values after 3 months".

C. The reviewer is right that it would have been valuable to include patients with other viral infections as controls, as we have clearly stated in the discussion (the penultimate paragraph). The findings of the present study give rise to controlled studies in the future. We were not quite sure if the reviewer wished for a table of the limitations of this study, but we did not make any, since there are already four tables in the manuscript.

Minor point: We have added a symbol " $>$ " and a parenthesis to the page 6, Results, line 5: "Acute impairment of renal function (maximum plasma creatinine concentration measured during hospital stay $>100 \mu \mathrm{mol} / \mathrm{l})$ was observed in $78 \%$ of the patients, and 3 needed transient dialysis therapy".

\section{Point-by-point responses to the comments by Reviewer 2}

The diagnosis of PUUV infection is based on serological tests, detection of PUUV IgM or low avidity of PUUV IgG. In Finland, PUUV is the only hantavirus that causes HFRS. We have now added a more detailed description of the serological test in the revised manuscript on page 4 , line 2 : "The original patient group consisted of 70 prospectively collected consecutive patients, hospitalized due to serologically verified acute PUUV infection at Tampere University Hospital, Finland, during the years 1997 to 1999. The specific serological diagnosis was based on an immunoglobulin M-capture enzyme immunoassay and PUUV Sotkamo strain full-length N protein expressed by using the baculovirus system in Sf9 insect cells [18]. In comparison with various other protocols the assay showed optimal sensitivity and specificity [19]". We have also added a new reference 19: Sjölander, K.B., Elgh, F., Kallio-Kokko, H et al. (1997) Evaluation of serological methods for diagnosis of Puumala hantavirus infection (nephropathia epidemica). J Clin Microbiol 35, 3264-3268. 